\title{
EARLY POSTERIOR SUBTALAR FUSION IN THE TREATMENT OF FRACTURES OF THE OS CALCIS
}

\author{
J. NOBLE, W. M. MCQUiLlAN
}

From The Royal Infirmary, Edinburgh

\begin{abstract}
Displaced fractures of the os calcis involving the subtalar joint frequently cause chronic disability due to subsequent osteoarthritis. Early posterior subtalar fusion may prevent this outcome. We have reviewed forty-seven fractures in forty-three patients at an average of seven years after operation. Over 90 per cent of patients had an excellent, good or satisfactory result.
\end{abstract}

Fractures of the os calcis with involvement of the subtalar joint may give rise to chronic pain and permanent functional incapacity. Earlier authors (Gallie 1943; Geckeler 1950; Essex-Lopresti 1952; Dick 1953; Harris 1963) advocated surgical treatment but more recently conservative care has been favoured (Lindsay and Dewar 1958; Lance, Carey and Wade 1963; Barnard and Odegard 1970; O'Connell, Mital and Rowe 1972; Nade and Monahan 1973).

Numerous attempts at classification of these fractures have been made (Böhler 1931; Warrick and Bremner 1953; Widen 1954; Thoren 1964; Gaul and Greenberg 1966). Many required special radiographs to distinguish between groups whose difference was of little practical significance. Dick (1953) argued that the extent of intra-articular destruction and displacement was the key to prognosis together with the degree of oedema and stiffness affecting the foot. We have devised a classification, based on these principles, which can be made from a routine lateral radiograph, and upon which treatment and prognosis can be based.
In 1953 Dick reported his preliminary experience with early posterior subtalar fusion. His successor (W. M. McQ.) has continued to use this method of treatment.

In this paper we present a classification of fractures of the os calcis and describe our experience with treatment of selected injuries by posterior subtalar fusion.

\section{Classification of fractures of the os calcis}

Grade I. Not involving the subtalar joint.

Grade IIA. Involving the subtalar joint but without significant displacement of the articular surfaces.

Grade IIB. Displacement of the articular surfaces with reduction or reversal of Böhler's angle (Böhler 1931). These fractures are usually either vertically compressed (Fig. 1) or angulated, with a "parrot beak" opening posteriorly (Fig. 2).

Grade III. Grossly comminuted, so that the general outline of the sinus tarsi is fragmented (Fig. 3).

Suggested treatment of the subgroups. Grade I and

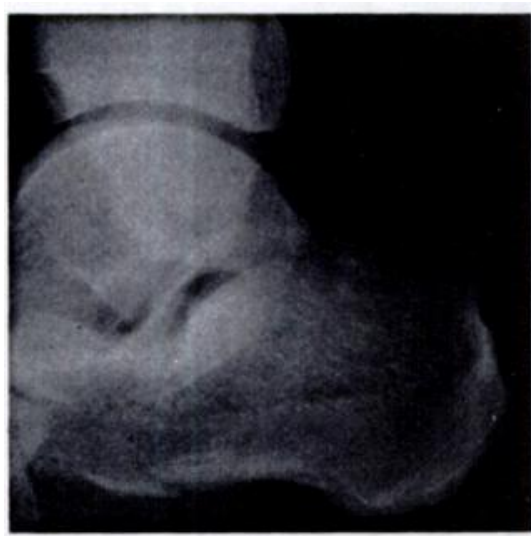

Fig. 1

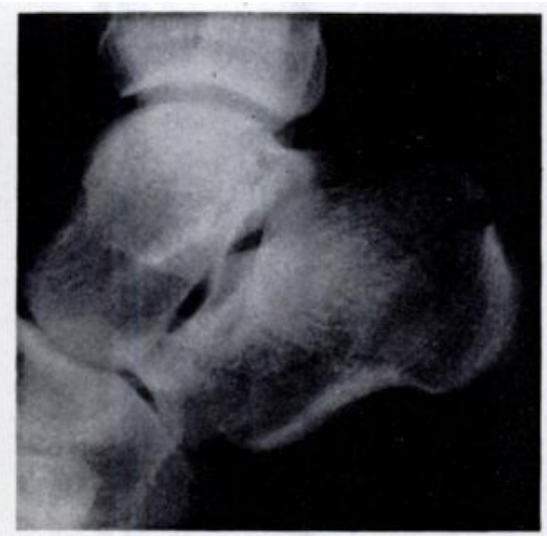

Fig. 2

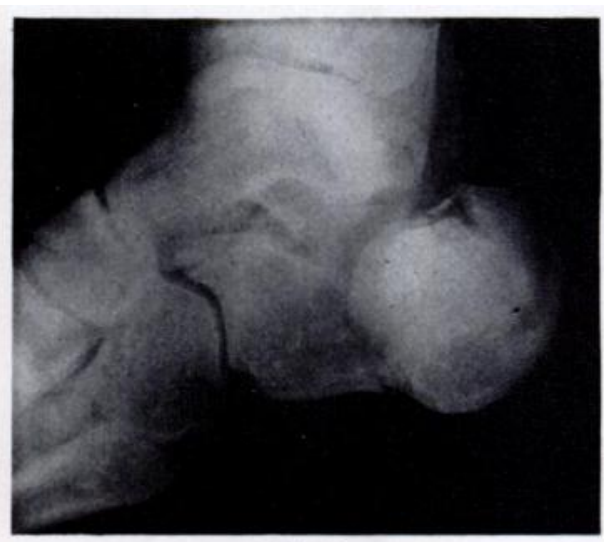

Fig. 3

Figure 1-Lateral radiograph showing Type IIB fracture of the os calcis with vertical compression. Figure 2-Lateral radiograph showing Type IIB fracture of the os calcis with "parrot beak". Figure 3-Lateral radiograph showing Type III fracture of the os calcis.

J. Noble, F.R.C.S.Ed., Senior Lecturer, Department of Orthopaedic Surgery, University of Manchester, Hope Hospital, Eccles Old Road, Salford M6 8HD, England.

W. M. McQuillan, F.R.C.S.Ed., Consultant Orthopaedic Surgeon, Royal Infirmary, Edinburgh EH3 9YW, Scotland.

Requests for reprints should be sent to Mr J. Noble. 
Grade IIA fractures require the prevention or relief of swelling and early mobilisation. Grade III fractures will inevitably progress to fibrous or sometimes bony ankylosis and should be treated like Grade I or Grade IIA injuries. Grade IIB fractures will eventually lead to

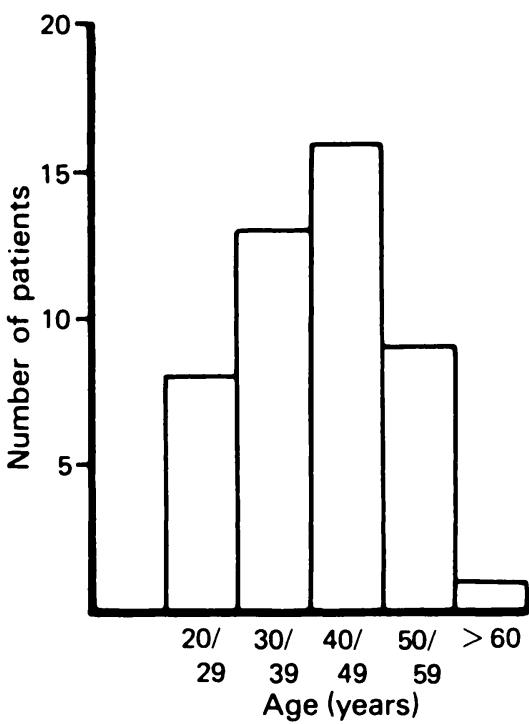

Fig. 4

Histogram showing age distribution of the patients reviewed.

osteoarthritis of the subtalar joint but will preserve sufficient movement of the joint to cause pain. We agree with Dick (1953) and Harris (1963) that early subtalar arthrodesis will prevent this outcome.

\section{PATIENTS AND METHODS}

The notes and radiographs of forty-five patients, with a total of fifty-one fractures, who had been treated by posterior subtalar arthrodesis between 1953 and 1973 were traced. Forty patients were seen and examined by the authors and three by other surgeons while two were untraceable. In all, the results of forty-seven fractures were assessed. Twenty-nine had been operated upon within one month and a further eight within eight weeks of injury.

Forty-five fractures were in men and two in women. Thirty men carried out a substantial part of their work on ladders or scaffolding. Eight were window cleaners. Thirty-eight of the fractures occurred because of a fall at work. The age distribution of the forty-three patients is shown in Figure 4 and the time to review in Figure 5. In only one patient was there an injury to the ipsilateral limb, a pertrochanteric fracture. There were three contralateral limb injuries other than fractures of the os calcis: a fracture of the shaft of the femur, a third-degree Pott's fracture and a fracture of the navicular. There were also four patients with wedge fractures of vertebrae, one with a fractured pelvis, and one young man suffered a severe abdominal injury, necessitating a Whipple's procedure.

In twenty-six fractures Böhler's angle was merely reduced in comparison with the opposite side (or was less than 20 degrees in bilateral injuries).

Five patients were referred to us already immobilised in below-knee plasters, one of which incorporated a Gissane spike. Otherwise all patients were treated before operation by elevation and compression bandaging of the leg.

Technique of operation. With the patient prone the posterior subtalar joint was exposed through an incision placed between the lateral malleolus and the calcaneal tendon. A triangular slot was cut approximately 2 centimetres by 1 centimetre at the base and extending as a wedge to the front of the joint, excising the cartilage and subchondral bone. Meanwhile an assistant cut two triangular wedges of corticocancellous bone from a posterior iliac crest. These wedges, measuring approximately 2.5 centimetres by 1 centimetre by 1

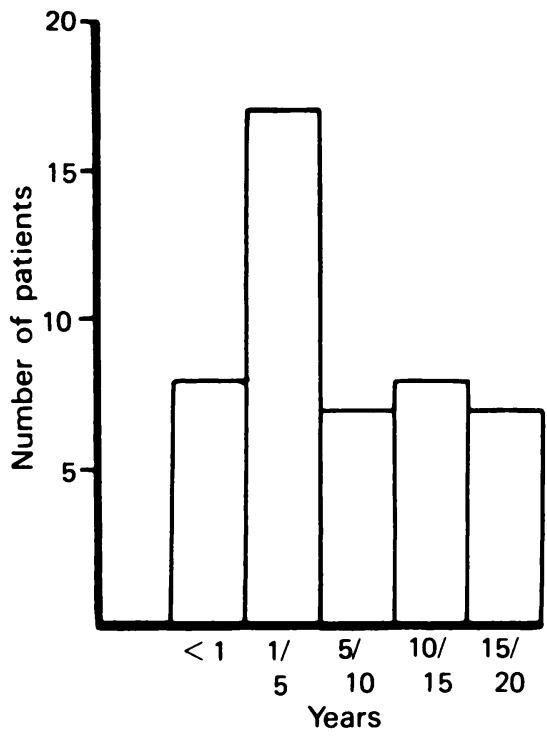

Fig. 5

Histogram showing length of follow-up of the patients reviewed.

centimetre, were then placed with their cortical surfaces back to back and punched into the prepared slot. The wound was closed and a wool and crepe compression dressing applied below the knee. Figure 6 shows a lateral radiograph of the subtalar joint one month after operation. The position of the wedge can be seen. A sound fusion is apparent two years later (Fig. 7).

Postoperative management. Twenty-two patients were allowed up on crutches, bearing no weight on the operated limb, in under two weeks, and a further seventeen in between two and four weeks. Four patients with bilateral fractures were longer in mobilising. All but nine were out of hospital within three weeks, the delay being due to other injuries. Twenty-eight patients were bearing full weight on the affected foot within eight weeks of operation and all but four, who had multiple injuries, within three months.

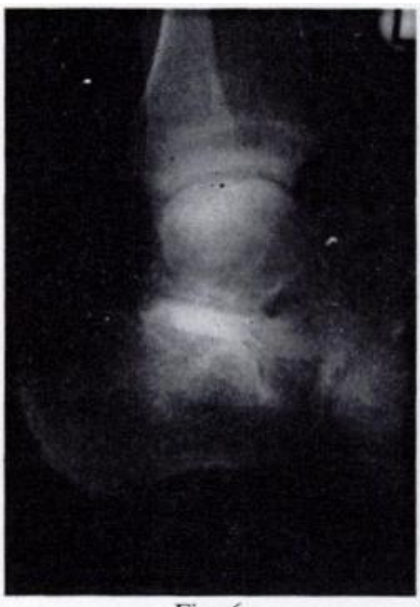

Fig. 6

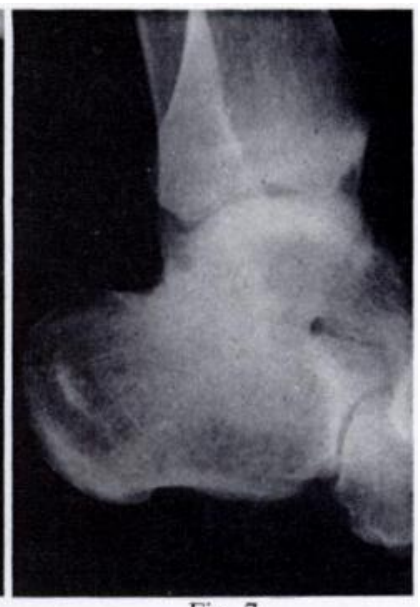

Fig. 7
Figure 6-Lateral radiograph one month after posterior subtalar fusion. Figure 7-Lateral radiograph two years after posterior subtalar fusion. 


\section{RESULTS}

When the patients were seen for review the result was classified as excellent, good, satisfactory or poor according to the criteria shown in Table I. Thirty-nine per cent were graded excellent, 17 per cent good, 35 per cent satisfactory and 9 per cent poor. One patient was not classifiable because of his poor mental and physical state at the time of review.

Table I. Criteria for grading results in patients reviewed

\begin{tabular}{|c|c|}
\hline Observations & Grading \\
\hline $\begin{array}{l}\text { No complaints or symptoms } \\
\text { No postoperative complications } \\
\text { Resumed original employment }\end{array}$ & Excellent \\
\hline $\begin{array}{l}\text { Difficulty with roofs or ladders only } \\
\text { Problems secondary to associated injuries } \\
\text { Minor postoperative complications } \\
\text { Return to original employment }\end{array}$ & Good \\
\hline $\begin{array}{l}\text { Mild ache on full weight-bearing for more than } \\
\text { one hour or after walking } 2 \text { miles or more. } \\
\text { Otherwise as for "good" }\end{array}$ & Satisfactory \\
\hline Failure to fulfil above conditions & Poor \\
\hline
\end{tabular}

Postoperative complications. Patients operated upon less than four weeks after injury ("Early") were distinguished from those who underwent operation after more than four weeks ("Late"). The complications encountered are listed in Table II. There was one major wound infection which took three months to heal. In another patient the graft was mistakenly driven into the posterior aspect of the ankle joint, fortunately with little damage. The operation was revised with a successful result. One non-union occurred when the graft was inadequately seated and successful revision was undertaken seven months after the first operation. One patient required late release of tethered medial tendons.

Symptoms at follow-up (Table III). Forty-four per cent of patients were free of symptoms and 37 per cent had no limit on their working or recreational activities. Pain, when present, was usually around the lateral malleolus. The heel lay in varus in two instances and in valgus in four. Twenty-six heels, in twenty-three patients, were broadened and wasting of the calf was present in twenty-two patients.

Return to employment. Two patients remained unemployed as a direct consequence of their calcaneal fractures. Associated injuries caused a change of job in two patients although one was about to work on an oil rig. Seven patients attributed their change of employment, at least in part, to injuries to the os calcis. Three of these had bilateral fractures, two having a Type III fracture to the other side. Two more of these seven had additional severe injuries. Four of the seven had undergone posterior subtalar fusion more than eight weeks after injury. Five patients had changed their job but not because of fracture of the os calcis. The remaining twenty-seven patients had returned to their former employment.

Comparison of "early" and "late" fusions. There were five complications in eighteen operations in the "late" group and in thirteen of twenty-nine "early" procedures but five wound infections occurred in the "early" group and only one in the "late". The mean time from operation to full rehabilitation was twenty-two weeks in both groups, which is similar to the results of Geckeler (1950) and Hall and Pennal (1960). Bilateral fractures did as well as unilateral injuries in both groups.

In those patients whose operation was more than ten years before follow-up there was a significant $(P<0.05)$ increase in excellent and good results and in the group seen less than ten years after operation there was a significant $(P<0.05)$ preponderance of satisfactory and poor results.

\section{DISCUSSION}

This method of treatment of displaced fractures of the os calcis involving the subtalar joint was previously described by Dick (1953), who advocated early posterior subtalar arthrodesis as soon as primary swelling had been controlled in fractures which were likely to result in painful osteoarthritis of the subtalar joint. Harris (1963) agreed with Dick and maintained that even if well-reduced the bony fragments were likely to undergo avascular change, thus increasing the degeneration of the subtalar joint. Wilson (1966) stated that the prognosis for comminuted and depressed fractures, and those involving the posterior articular facet, was best in

Table II. Postoperative complications

\begin{tabular}{|l|c|c|}
\hline \multicolumn{1}{|c|}{ Complications } & Early group & Late group \\
\hline Haematoma & 4 & 3 \\
Delayed wound healing & 1 & 0 \\
Wound infection & 5 & 1 \\
Deep vein thrombosis & 2 & 0 \\
Delayed union & 1 & 0 \\
Misplaced graft & 0 & 1 \\
Number of complications & $13 / 29$ & $5 / 18$ \\
Number of patients with complications & $10 / 25$ & $\begin{array}{c}5 / 18 \\
(40 \text { per cent })\end{array}$ \\
& $(28$ per cent $)$ \\
\hline
\end{tabular}

injuries treated by early subtalar fusion, but he had few patients and gave brief clinical details. Thompson and Friesen (1959) and Zayer (1969) considered that osteoarthritis of the calcaneocuboid and talonavicular joints inevitably occurred and advocated early triple fusion. Their results after operation were similar to our own. However, we have not encountered osteoarthritic 
Table III. Symptoms at follow-up

\begin{tabular}{|l|r|r|}
\hline & Number & Per cent \\
\hline Asymptomatic & 19 & 44 \\
No limit on any activity & 16 & 37 \\
Activity limited because of os calcis fracture & 10 & 23 \\
Difficulty with stairs or ladders & 17 & 40 \\
Pain when not weight-bearing & 3 & 7 \\
Pain after 2 miles or 1 hour of weight-bearing & 12 & 28 \\
Pain after less than 2 miles or 1 hour & 7 & 16 \\
Pain in heel & 2 & 5 \\
Pain about lateral malleolus & 19 & 44 \\
Pain about medial malleolus & 1 & 2 \\
Uses a stick & 1 & 2 \\
\hline
\end{tabular}

changes in the other tarsal joints and consequently do not consider a prophylactic triple fusion justifiable. Indeed, we found a significantly higher incidence of excellent or good results in patients followed up for ten years or more, and none of our patients has subsequently required a triple arthrodesis. Several patients described lessening of pain and improvement in activity five or more years after operation and similar findings were noted by Lindsay and Dewar (1958).

We have found difficulty in assessing the results of those who advocate conservative treatment because of the differing classifications used and the inadequacy of follow-up in some series. However, no authors mentioned in this paper as favouring conservative treatment have been able to approach our results of over 90 per cent of patients returning to the same or similar work within six months of injury.

We therefore believe that posterior subtalar fusion should be undertaken between two and four weeks after injury in order to allow early return of satisfactory function, thus avoiding the damaging psychological and economic effects of delayed fusion or conservative care. Analysis of our results shows a notable incidence of minor postoperative complications and 6 per cent of patients required further operation but we consider these risks justifiable in view of the high level of success achieved.

This plan of management was originated by the late Mr Ian Lawson Dick. We are grateful to Mr M. A. Leonard and Mr W. B. Clark for reviewing three of the patients.

\section{REFERENCES}

Barnard, L., and Odegard, J. K. (1970) Conservative approach in the treatment of fractures of the calcaneus. Journal of Bone and Joint Surgery, 52-A, 1689.

Böhler, L. (1931) Diagnosis, pathology and treatment of fractures of the os calcis. Journal of Bone and Joint Surgery, 13, 75-89.

Dick, I. L. (1953) Primary fusion of posterior subtalar joint in the treatment of fractures of the calcaneum. Journal of Bone and Joint Surgery, 35-B, 375-380.

Essex-Lopresti, P. (1952) The mechanism, reduction technique, and results in fractures of the os calcis. British Journal of Surgery, 39, $395-419$.

Gallie, W. E. (1943) Subastragalar arthrodesis in fractures of the os calcis. Journal of Bone and Joint Surgery, 25, $731-736$.

Gaul, J. S., Jun., and Greenberg, B. G. (1966) Calcaneus fractures involving the subtalar joint. Southern Medical Journal, 59, 605-613.

Geckeler, E. O. (1950) Comminuted fractures of the os calcis. Archives of Surgery, 61, 469-476.

Hall, M. C., and Pennal, G. F. (1960) Primary subtalar arthrodesis in the treatment of severe fractures of the calcaneum. Journal of Bone and Joint Surgery, 42-B, 336-343.

Harris, R. I. (1963) Fractures of the os calcis: treatment by early subtalar arthrodesis. Clinical Orthopaedics and Related Research, 30, $100-110$.

Lance, E. M., Carey, E. J., Jun., and Wade, P. A. (1963) Fractures of the os calcis: treatment by early mobilization. Clinical Orthopaedics and Related Research, 30, 76-90.

Lindsay, W. R. N., and Dewar, F. P. (1958) Fractures of the os calcis. American Journal of Surgery, 95, 555-576.

Nade, S., and Monahan, P. R. W. (1973) Fractures of the calcaneum: a study of the long-term prognosis. Injury, 4, $200-207$.

O'Connell, F., Mital, M. A., and Rowe, C. R. (1972) Evaluation of modern management of fractures of the os calcis. Clinical Orthopaedics and Related Research, 83, 214-223.

Thompson, K. R., and Friesen, C. M. (1959) Treatment of comminuted fractures of the calcaneus by primary triple arthrodesis. Journal of Bone and Joint Surgery, 41-A, 1423-1436.

Thoren, O. (1964) Os calcis fractures. Acta Orthopaedica Scandinavica, Supplement 70.

Warrick, C. K., and Bremner, A. E. (1953) Fractures of calcaneum. Journal of Bone and Joint Surgery, 35-B, 33-45.

Widén, A. (1954) Fractures of the calcaneus. Acta Chirurgica Scandinavica, Supplement 188.

Wilson, D. W. (1966) Functional capacity following fractures of the os calcis. Canadian Medical Association Journal, 95, 908-911.

Zayer, M. (1969) Fracture of the calcaneus. Acta Orthopaedica Scandinavica, 40, 530-542. 